\title{
The Triad "Cause-Mean-Effect" as a Way of Approximating the Efficiency of Technical or Non-technical Creations or Systems
}

\author{
Marius Arghirescu \\ State Office for Inventions and Trademarks, Bucharest, Romania
}

Email address:

arghirescu.marius@osim.ro

\section{To cite this article:}

Marius Arghirescu. The Triad "Cause-Mean-Effect" as a Way of Approximating the Efficiency of Technical or Non-technical Creations or Systems. International Journal of Philosophy. Vol. 8, No. 1, 2020, pp. 8-14. doi: 10.11648/j.ijp.20200801.12

Received: February 1, 2020; Accepted: February 24, 2020; Published: February 28, 2020

\begin{abstract}
The paper presents a method of approximating the efficiency of a Cause-Mean-Effect (CME) triad of technical or non-technical nature, which may be used in the phylosophy of technology, especially to estimate the effects over a longer period of time of a CME triad with cyclical and variable evolution. The method consists in the studying of the CME triad's evolution by a graphical representation with three axes in which the position on its axis of representation of the cause $\mathrm{C}$ or of the effect $\mathrm{E}$ indicates its intensity and the position on its axis of representation of the mean $\mathrm{M}$ represents its value expressed by the maximal possible intrinsic negentropy: $\mathrm{O}_{M}=-\mathrm{S}_{\mathrm{M}}$ and by its reliability $\mathrm{p}(\tau)$, the efficiency of the CME triad being approximated in a simplified form as given by the product of the ratios (E/M) and (E/C). The use value of the mean $M$ can be empirically but generally approximated by a relation: $M=K_{M} S_{M} \cdot p(\tau)$ wherein $K_{M}$ is a quasi-constant of proportionality whose value is inversely proportional to the value of the utilities necessary for the maintaining of the reliability $\mathrm{p}(\tau)$ of the M-mean and which may be taken also with decreasing value- in the case of a relative triad. There are presented examples of studying the efficiency of CME triads associated with technical or non-technical or mixed systems, which reveals the possibility of the method's using in the theory of technical or non-technical systems, in particular - in assessing the risk of the society's regression by the degrading of the environment by irrational using of some technologies or by the excessive exploitation of natural resources. It is evidenced also the link with the known principle of "agglomeration of results", by the variant of "tetradic CME triad", with two different but useful effects, E1, E2, obtained by a single cause C and a single mean M.
\end{abstract}

Keywords: Cause-Mean-Effect Triad, Phylosophy of Technology, Creation's Efficiency, System's Reliability, Praxiology

\section{Introduction}

It is currently discussed in the society of philosophers about the so-called "philosophy of technology". Philosophy of technology is a sub-field of philosophy that study the nature of technology and its social effects. The term "philosophy of technology" was first used in the late 19th century by German philosopher and geographer Ernst Kapp from Texas, (USA), [1]. The western term "technology" comes from the Greek term "techne" ( $\tau \dot{\varepsilon} \chi \nu \eta$-art or craft knowledge), and the roots of philosophical views on technology can be found in the roots of Western philosophy. A common theme in the Greek vision of "techne" is that it appears as an imitation of nature (for example, the weaving technique that mimics the spider's weaving technique).
Studies of the philosophy of technology include interest in various topics of geoengineering, internet and confidentiality, technological function and epistemology of technology, computer ethics, biotechnology and its implications, transcendence in space and technological ethics, how technological progress affects human society and culture, and so on.

Technological determinism is based on the idea that the particularities of the technology determine its use and the role of a progressive society is to adapt to and benefit from technological change, [2]. An alternative perspective would be the social determinism that regards society as being responsible for the development and evolution of the technologies [2].

In direct connection with this philosophical aspect is the 
problem of the efficiency of technological creations such as inventions, innovations (utility models). Because these technical creations represent new and inventive technical solutions to known or new technical problems, aiming at the conversion of technical or non-technical C- causes (eg. natural causes such as the wind energy) in effects $\mathrm{E}$ useful for the society (the obtaining of electricity, etc.), it appears the social-technological problem of the efficiency of the triad: Cause-Mean-Effect, (CME), problem that it is generally related to the general evolution of human society (evolution that involves technological progress but is not limited to it), and in particular it is related to the technological evolution of the society and implicitly- to the field of the philosophy of technology.

The distinction between a non-technical CME and a technical triad consists in that in the case of a technical CME triad, at least the means by which the cause generates effect(s) is of technical nature.

The correspondence in the patent law of the invention of this particular feature of the technical CME triads is the legal provision that a patent may be granted for any invention having as object a product or a process in any technological field, which is new, inventive and susceptible of industrial application and that the discoveries, the scientific theories and mathematical methods, the aesthetic creations, the plans, principles and the methods in the exercise of mental activities, in the field of games or in the field economic activities, are not considered inventions.

\section{The Approximating of the Efficiency of a Triad Cause-Mean-Effect}

The social efficiency of a CME-triad will be given by all three components of it. This efficiency can be approximated by means of a graphical representation with three axis, starting from the general concept of Triad in which the three interdependent characteristics can generate a stable relation, in closed triangle, (S. Baiculescu, [3]), but considering a cyclic and variable evolution, through the following general technical-philosophical considerations:

1. The position on its axis of the representation of the cause $\mathrm{C}$ or of the effect $\mathrm{E}$ indicates its intensity;

The useful effect is considered positive and the harmful effect is considered negative.

2. The position on its axis of the representation of the mean $\mathrm{M}$ represents its use value expressed by the amount of maximal negentropy $\left(-S_{M}\right)$ included by the mean $M$, (usually: material values + labor) and its reliability, $p(\tau)$; In technique, the mean $\mathrm{M}$ is a technical solution to a technical problem, that is- an invention or an innovation, (utility model);

3. The ratio between the area of the equilateral triangle with the side equal to the intensity $E$ of the effect, $A_{E}$ and the effective area $A_{e}$ of the triangle CME gives the efficiency, $\in=\mathrm{A}_{E} / \mathrm{A}_{\mathrm{e}}$; in a simplified semi-empiric form we may take:

$$
\epsilon \approx(\mathrm{E} / \mathrm{M}) \cdot(\mathrm{E} / \mathrm{C})=\mathrm{E}^{2} / \mathrm{M} \cdot \mathrm{C}
$$

In particular: $\in \geq 1$ - efficient triad, $\in<1$-partially efficient or inefficient triad;

In a stationary but relative $\mathrm{CME}$ triad, $\in^{\mathrm{r}}$, the mean $\mathrm{M}$ may be variable compared to a stationary similar triad.

4. The CME triad to which the E- effect increases continuously in intensity or decreases continuously until cancellation, represents an unstable ascending/(decreasing) triad;

5. The CME triad whose evolution ends with a stable cycle (a closed triangle $\mathrm{C}_{\mathrm{k}} \mathrm{M}_{\mathrm{k}} \mathrm{E}_{\mathrm{k}}$ with the same point $\mathrm{E}$ ) represents a stabilized ascending/decreasing CME triad;

6. The CME triad whose evolution is partly ascending and partly descending represents an oscillatory triad;

7. The $\mathrm{C}_{\mathrm{K}} \mathrm{M}_{\mathrm{k}} \mathrm{E}_{\mathrm{k}}(\mathrm{k}=1,2,3 . . \mathrm{n})$ triad of a multi- cyclic CME triad represents the $\mathrm{c}_{\mathrm{k}}\left(\tau_{\mathrm{k}}\right)$ cycle of the triad, having the period $\tau_{\mathrm{k}},\left(\mathrm{c}_{\mathrm{k}}\left(\tau_{\mathrm{k}}\right)=(\mathrm{cme})_{\mathrm{k}}\right)$;

8. The efficiency of a multi-cycle CME triad is given by the average efficiency, (sum of the efficiencies of the cycles $\mathrm{c}_{\mathrm{k}}$ divided by the number of cycles, $\mathrm{n}_{\mathrm{c}}$ ):

$$
\epsilon_{\mathrm{T}}=\Sigma \epsilon_{\mathrm{k}} / \mathrm{n}_{\mathrm{c}},(\mathrm{k}=1,2 . . \mathrm{n}) ;
$$

9. The CME triad in which the E effect is a non-technical effect is a non-technical triad and the triad in which the $\mathrm{E}$ effect is a technical effect is a technical triad; The CME triad with at least one technical effect and at least one nontechnical effect represents a mixt triad.

We may use- in a simplified way, for a specific associated CME triad, the notation: $\Delta_{\mathrm{L}}=\mathrm{C}_{\mathrm{L}} \mathrm{M}_{\mathrm{L}} \mathrm{E}_{\mathrm{L}}$.
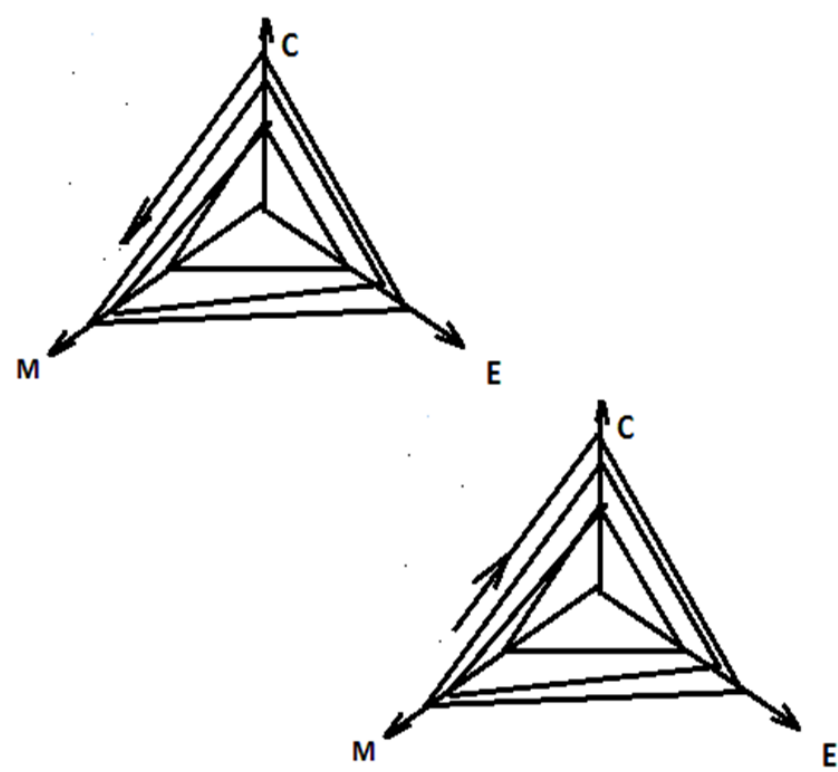

Figure 1, a, b, ascending un-stabilized CME triad, a) and descent stabilized CME triad, $b$ ).

\section{Examples of CME Triads}

A. Examples of non-technical CME triads:

A1: The specialization (training) with the help of the computer

As it is known, purely mental activities, such as business plans, musical compositions, computer programs, literary 
works or rules of play, etc., are non-technical activities, excluded from patentability, according to the law of inventions, although they can use technical products such as a computer or a telephone as an auxiliary device, for example. The associated CME triads are also non-technical.

The training process uses a non-technical CME triad, usually- ascending-stabilized, $\Delta_{\mathrm{L}}{ }^{\mathrm{a}}$, consisting in that a smaller initial volume of information/knowledge (initial cause, $\mathrm{C}_{1}$ ) is assimilated through human means (teachers, speakers) or/and by technically means (computer, video projector, etc.) which are used for training/specialization (effect, E) in correlation with the previous life and the professional experience, this effect $E$ allowing the accumulation of new information/specialized knowledge (forming the $\mathrm{C}_{2}$ subcyclic cause), of increased volume $\left(\mathrm{C}_{2}>\mathrm{C}_{1}\right)$ which can generate a greater training cycle effect, $\left(\mathrm{E}_{2}>\mathrm{E}_{1}\right)$, the triadic cycle being repeated until a final cycle which stabilizes the CME training triad, characteristic to the change of profession or to the retirement of the trained, (to an old age).

\section{A2. The developing of a business}

In the development of a business, the purpose (the effect E) pursued is usually to obtain profit, an effect that allows the development of the company and the business. This business development can also start with a small firm, with 2-4 employees (of start-up or spin-off type) and with a modest technical-material endowment, which together form the) initially mean $\mathrm{M}_{1}$ (formed as assembly of means). Of course, the $M_{1}$-means must be used intelligently, rationally, according to a business plan that together with an initial investment fund $F_{1}$ represents- within the CME triad, the initial cause $\mathrm{C}_{1}$.

In the context in which the $C_{1}$ cause (whose intensity can be appreciated through the investment fund $\mathrm{F}_{1}$ ) generates- through the $\mathrm{M}_{1}$ means, an $\mathrm{E}_{1}$ effect whose intensity can be appreciated through the $V_{1}$ income, if $V_{1}>F_{1}$, will result that $E_{1} / C_{1}>1$ and the evolution the specific CME triad results in this case as ascending to the cycle $c_{1}$. However, the efficiency of the CME triad also depends on the value of the M- means, which - since it also includes human resources - is proportional to the $\mathrm{S}_{1}$ salary expenses of the employees, during the time period of the $\mathrm{c}_{1}$ cycle: $\in \approx \mathrm{E}^{2} / \mathrm{M} \cdot \mathrm{C}$. If $\mathrm{E}_{1} / \mathrm{M}_{1}<1,\left(\mathrm{~S}_{1}\right.$ - wage costs higher than $\mathrm{V}_{1}$ - income), it results that $\epsilon_{1} \approx \mathrm{E}_{1}{ }^{2} / \mathrm{M}_{1} \mathrm{C}_{1}<1$, i.e. an inefficient triad for (sub)cycle $c_{1}$. In order to make the triad more efficient, it is therefore necessary that the $\mathrm{S}$-salary expenses be lower than the $\mathrm{V}$ - income, resulting in this case a benefit $\mathrm{B}=\mathrm{V}-\mathrm{S}$ which, summed over a given number of cycles $c_{k}$, will amortize the initial investment $F_{1}$ and will bring the company to a profit: $\mathrm{P}=\mathrm{V}_{\mathrm{T}}-\mathrm{S}_{\mathrm{T}}-\mathrm{F}_{1}$.

The specific CME triad will be profitable in this case, and if the $\mathrm{P}$ profit is maintained at a quasi-constant value, the specific CME triad results as of stabilized ascending type. Otherwise it is of oscillatory type.

\section{A3: The Nature-Human-Society (NOS) relation}

The CME triad (cause-mean-effect) associated to the Nature-Human-Society (NOS) relation explains the harmonic or an-harmonic development of the society by the fact that the Nature, by its natural resources $\mathrm{R}_{\mathrm{i}}$ (the initial cause, $\mathrm{C}_{1}$ ), through human individuals (the mean $\mathrm{M}$ ) contributes to the well-being and the biological, psychological and moral health of the society as a whole, (the effect E pursued). The harmonic development of the society is greater when the potential for rational use of the natural and individual resources (social-useful value of individuals) is greater, case which can ensure an upward evolution of the CME triad associated with the NOS relationship by maintaining the balance of the Nature at adequate values of regeneration of natural resources (physical, vegetable, animal, fish, etc.), up to a stabilized cycle $c_{n}$ given by the fact that the society, through its individuals, ensures the maintaining of the level of natural resources by greening and regeneration, or it can increase this level, for example - by the transformation of some initially arid areas into agricultural areas, by favoring the propagation of useful species, etc.

In order to express the efficiency of the associated CME triad: $\in \approx \mathrm{E}^{2} / \mathrm{M} \cdot \mathrm{C}$, it is necessary that the human $\mathrm{M}$ - means be expressed by the amount of natural resources $M_{r}$ consumed directly or indirectly by each individual (necessary to maintain their social-useful value) and by their spiritual value $M_{V}: M=\Sigma M_{r} \cdot M_{V}$, for example by their negentropy, $-S$.

The efficiency of the associated CME triad: $\epsilon_{\mathrm{k}}$ will be greater on a $c_{k}\left(\tau_{k}\right)$ cycle of the triad when the ratio $(E / M)$ or/and (E/C) will be higher, so- when more individuals in an agricultural company- for example, (in a farm), produce an $E_{k}$ effect useful for the welfare of the company with a lower consumption of natural resources $\delta \mathrm{R}_{\mathrm{k}}$, the time period $\mathrm{T}_{\mathrm{a}}\left(\mathrm{T}_{\mathrm{s}}\right)$ of ascending or relative stable evolution of the associated CME triad depending to the total natural resources $R_{T}$ available to the respective company:

$$
\mathrm{T}_{\mathrm{s}} \approx \mathrm{R}_{\mathrm{T}} / \delta \mathrm{R}_{\mathrm{k}} \text {. }
$$

This last condition imply also the preservation of the natural environment and of the total natural resources $\mathrm{R}_{\mathrm{T}}$.

Because the natural resources are realistically declining, it logically follows that for obtain a longer period $T_{a}\left(T_{s}\right)$, the members of the company must reduce the specific consumption of natural resources over a given period of time, characteristic of the restoration of these natural resources $R_{T}$, in accordance also with the philosophical conclusions regarding the general case of a cyclical CME- triad.

A4: The malpractice increasing in the social life

An example of ascending managerial CME triad is the managerial malpractice increasing (the effect $\mathrm{E}$ ) generated by a lack of legislative provision (the cause C) by the action of the manager of a political, economical or administrative state institution (the mean $\mathrm{M}$ ), which- by the cause $\mathrm{C}$, having a low value of reliability $\mathrm{p}(\tau)$ (i.e.- a low use value $M$ ), use abusively the incomes of the state institution for personal use. If this effect $\mathrm{E}$ is not sufficiently punished by a judicial court, it may increase by repetition, by a lower $p(\tau)$, in a next (cme) cycle, generating managerial corruption and dangerous malpractice, in particular- the institution's bankruptcy.

A5: The tree

A tree may be considered as a biological ascending CME triad in which a quantity $\mathrm{q}_{1}$ of water with mineral salts and 
the initial seed represents toghether the initial cause $\mathrm{C}_{1}$ which -by a quantity $\mathrm{k}_{1}$ of carbon dioxide from air and solar energy, forming the mean $\mathrm{M}_{1}$, is converted into a little tree (the effect $E_{1}$ ), by vegetal cells multiplication, which toghether with a new quantity $\mathrm{q}_{2}>\mathrm{q}_{1}$ of water with mineral salts will represent the successive cause $\mathrm{C}_{2}>\mathrm{C}_{1}$ determining the successive effect $E_{2}>E_{1}$ of the tree's growing by a successive quantity $\mathrm{k}_{2}>\mathrm{k}_{1}$ of carbon dioxide and solar energy- representing the successive mean $\mathrm{M}_{2}>\mathrm{M}_{1}$ and so on, until the tree's death.

B. Examples of technical CME triads:

B1: Periodic conversion of the potential energy of a weight $G$ into kinetic energy by a technical mean.

A pendulum is an example of technical mean $\mathrm{M}$ of a CME triad. In this case, the value of the weight $G$ and the height $h$ at which it is raised give the intensity of the cause, $C(G, h)$, and the value of the kinetic energy $\mathrm{K}$ at the lowest position of the weight $G$ gives the intensity of the effect $E(K)$, which becomes cause for the lifting of the weight $\mathrm{G}$ by transforming it into potential energy, the process being repeated. However, as it is known, due to the losses by air friction and weight bearing, the kinetic energy $\mathrm{K}$ obtained by free fall of the weight $G$ of the pendulum is slightly less than the potential energy $U$ from the beginning of the free falling, so that the oscillation of the pendulum is decreased over a period of time $\mathrm{t}$ which is inverse proportional with the difference between the initial potential energy (cause $C$ ) and the kinetic energy resulting from it (effect $E$ ), i.e.- a ratio between $A_{E}$ and $A_{e}$ smaller than 1 when the $\mathrm{C}$-cause is greater than the effect $\mathrm{E}$.

Because for the maintaining of the pendulum's motion is necessary to transform the unstable descending CME triad into a stabilized CME triad by giving periodically an additional energy to the weight $\mathrm{G}$, equal to the difference between $\mathrm{C}$ and $\mathrm{E}$, for example - by magnetic attraction during transformation, it is explained that the efficiency of the pendulum is lower when the ratio $\mathrm{A}_{E} / \mathrm{A}_{e}$ of the $\mathrm{CME}$ triangle corresponding to a half-period of the oscillation is lower, because the value $M$ of the technical means of the CME triad contributes to the efficiency' value: $\in=A_{E} / A_{e}$ by the fact that a more expensive source of energy necessary for loss compensation decreases the ratio: $\in \approx \mathrm{E}^{2} / \mathrm{M} \cdot \mathrm{C}$ corresponding therefore to a less technically efficient $\mathrm{CME}$ triad.

\section{B2. The cascade amplification of audio signal} (microphone amplifier):

- In this case, the initial cause $C_{1}$ is the intensity $I_{1}$ of the electrical signal of sound conversion through the microphone, which is transformed into an amplified electrical signal $I_{2}$, (effect $E_{1}$ ), through a first technical means $\mathrm{M}_{1}$ type electronic audio amplifier. The amplified signal $\mathrm{I}_{2}$ becomes - through a new $\mathrm{M}_{2}$ audio amplifier stronger than $M_{1},\left(M_{2}>M_{1}\right)$, a secondary cause $\left(C_{2}\right)$ to the obtaining of a new amplified electrical signal $\mathrm{I}_{3}$, etc., an finally obtained audio signal $\mathrm{I}_{\mathrm{n}}$ being converted into sound with a radio speaker.

The CME triad specific to this electronic amplifier type audio system represents an example of stabilized CME triad in which each cycle $c_{k}(k=1,2, . . n)$ gradually increases both the intensity of the $C_{k}$ cause and the intensity of the $E_{k}$ effect (as well as the use value of the mean $\mathrm{M}_{\mathrm{k}}$ ).

Similar to the previous case, the efficiency of the CME triad is given by the average efficiency, $\in_{T}$, resulted from the efficiency $\epsilon_{\mathrm{k}}=\mathrm{A}_{\mathrm{Ek}} / \mathrm{A}_{\mathrm{ek}}$ of each cycle $c_{\mathrm{k}}$, which is inversely proportional to the area of the triangle $C_{k} M_{k} E_{k}$ by the fact that for a given effect $E_{k}$ (the output current $I_{k+1}$ of the amplifier $\mathrm{M}_{\mathrm{k}}$ ), the efficiency of the corresponding CME triad is higher by a lower value of the cause $C_{k}$, (the input current $I_{k}$ ), if the value of the mean $M_{k}$ is approximately the same. Also, if a given $E_{k}$ effect is obtained by the same $C_{k}$ cause but with a more expensive $M_{k}$ means, the associated CME triad is less efficient as technical triad.

\section{B3: The production of nuclear fission energy:}

In the case of nuclear power generation by nuclear fission in chain, in which from three initial fission neutrons of ${ }^{235} \mathrm{U}$ nucleus (cause C) at least one produces the fission of another ${ }^{235} \mathrm{U}$ nucleus, (effect $\left.\mathrm{E}\right)$, depending on the technical means $\mathrm{M}$ which can be a nuclear reactor or a nuclear bomb, we have in the first case a stabilized CME triad (in which the reaction is controlled so as it not exceed the multiplication factor equal to the unit) and in the second case we have an un-stabilized ascending CME triad, in which the cause $\mathrm{C}$ (fission of $\mathrm{a}^{235} \mathrm{U}$ nucleus) generates a larger effect (by the fission of other 2 or $3{ }^{235} \mathrm{U}$ nuclei for each previously fissioned ${ }^{235} \mathrm{U}$ nucleus, which in turn will generate the fission of $4 \div 6$ nuclei of ${ }^{235} \mathrm{U}$ ), with the production of chain reaction and nuclear explosion.

From the point of view of the efficient production of nuclear energy, the CME2 triad (specific to the atomic bomb with nuclear fission) is more efficient than the triad CME 1 (specific to the nuclear reactor energy production), because overall, the same amount of energy generated by the same quantity of nuclear fuel of ${ }^{235} \mathrm{U}$ as the core of a nuclear reactor is released by a considerably cheaper mean (a nuclear bomb), the $\mathrm{E}^{2} / \mathrm{CM}$ ratio being thus higher, but with the particularity that this energy is released explosively and not gradually, in a controlled manner.

If it is desired the controlled use of nuclear energy, for conversion into electricity, it is obvious that in relation to this objective, which will represent the desired effect ( $\left.E^{\prime}\right)$ in this case, the use of a nuclear reactor is more efficient, because even if it is much more expensive, it ensures the obtaining of the desired effect $\mathrm{E}^{\prime}$, the ratio $\mathrm{E}^{\prime} / \mathrm{C} \cdot \mathrm{M}$ being higher in the case of the CME1 triad than in the case of the CME2 triad, in this case, as consequence of a different desired effect, E'.

In conclusion, the efficiency of the triad is a characteristic relative to the objective for which it is used, identifiable with the pursued effect $\mathrm{E}$.

If the pursued objective is the obtaining of an E- effect that can be produced with a technical M- mean, this efficiency also characterizes the technical efficiency of the technical means specific to the respective CME- triad.

B4: The generating of light by an electric bulb:

The associated CME- triad of the conversion of electric energy $\left(\mathrm{W}_{\mathrm{E}}=\mathrm{t} \cdot \mathrm{P}_{\mathrm{c}}\right.$-the cause $\mathrm{C}$; P-the electric power) into light (the effect $\mathrm{E} \cong \mathrm{t} \cdot \mathrm{P}_{1} ; \mathrm{P}_{1}$ - the light's power) by an electric 
bulb (the mean $M$ ) is generally more efficient for a bulb with LEDs, $\mathrm{M}_{\mathrm{L}}$, than those of a bulb with filament, $\mathrm{M}_{\mathrm{F}}$, because the same light power $\mathrm{P}_{\mathrm{E}}$ is obtained with a lower electric power consumption: $\mathrm{P}_{\mathrm{cL}}<\mathrm{P}_{\mathrm{cF}}$.

The associated CME triads: $\Delta_{\mathrm{L}}$ and $\Delta_{\mathrm{F}}$ are stationary, (Econstant), but the triad $\Delta_{\mathrm{L}}$ may be considered as a relative $\operatorname{triad} \Delta_{\mathrm{L}}{ }^{\mathrm{r}}$ with a relative efficiency: $\in_{\mathrm{L}}{ }^{\mathrm{r}}=\mathrm{t} \cdot \mathrm{P}_{1}{ }^{2} / \mathrm{P}_{\mathrm{cL}} \mathrm{M}_{\mathrm{L}}$.

Generally, for $\mathrm{t}=1 \mathrm{hr}$, considering the same cause' intensity: $\mathrm{C} \cong \mathrm{P}_{\mathrm{c}}, \in_{\mathrm{L}}>\in_{\mathrm{F}}$ imply, according to eqn. (1), that:

$$
\left(\mathrm{P}_{1 \mathrm{~L}}^{2} / \mathrm{M}_{\mathrm{L}}\right)>\mathrm{P}_{1 \mathrm{~F}}^{2} / \mathrm{M}_{\mathrm{F}}
$$

But because generally a bulb with LEDs is sensible more expensive than a bulb with filament, its use value: $M_{L}>M_{F}$ may be enough higher also than those necessary for give from the beginning, on a short period of use, a more efficient CME triad $\Delta_{\mathrm{L}}$ or equal with those of a bulb with filament, $\Delta_{\mathrm{F}}$, if: $\mathrm{M}_{\mathrm{L}} \mathrm{P}_{\mathrm{L}}>\mathrm{M}_{\mathrm{F}} \mathrm{P}_{\mathrm{F}}$.

But in the expression (1), because the amortization of costs difference by electric energy economy, in the relative triad $\Delta_{\mathrm{L}}^{\mathrm{r}}$ we must use a decreasing use value:

$$
\mathrm{M}_{\mathrm{L}}^{*}=\mathrm{M}_{\mathrm{L}}^{0}-\mathrm{k}_{\mathrm{p}} \Delta \mathrm{P}_{\mathrm{c}} \cdot \mathrm{t} ; \quad \Delta \mathrm{P}_{\mathrm{c}}=\left(\mathrm{P}_{\mathrm{cF}}-\mathrm{P}_{\mathrm{cL}}\right) ; \mathrm{t} \leq \mathrm{t}_{\mathrm{a}}
$$

$\mathrm{k}_{\mathrm{p}}$ being the costs of $1 \mathrm{KWh}$ and $\mathrm{t}_{\mathrm{a}}$-the period until the amortization of the supplentary costs $\Delta \mathrm{M}=\mathrm{M}_{\mathrm{F}}-\mathrm{M}_{\mathrm{L}}{ }^{0}$ :

$$
\Delta \mathrm{M}=\mathrm{M}_{\mathrm{L}}^{0}-\mathrm{M}_{\mathrm{F}}=\mathrm{k}_{\mathrm{p}} \Delta \mathrm{P}_{\mathrm{c}} \cdot \mathrm{t}_{\mathrm{a}} ; \quad \mathrm{t}_{\mathrm{a}}=\Delta \mathrm{M} / \mathrm{k}_{\mathrm{p}} \Delta \mathrm{P}_{\mathrm{c}}
$$

The time moment $\mathrm{t}_{\mathrm{e}}$ at which the $\Delta_{\mathrm{L}}$ triad is as efficient as $\Delta_{\mathrm{F}}$ is given by eqns. (1)- (4) for: $\epsilon_{\mathrm{L}}^{\mathrm{r}}=\epsilon_{\mathrm{M}} ; \mathrm{P}_{\mathrm{IL}}=\mathrm{P}_{\mathrm{lF}}$, i.e.:

$$
\begin{gathered}
\mathrm{M}_{\mathrm{L}}^{*}=\mathrm{M}_{\mathrm{F}} \mathrm{P}_{\mathrm{cF}} / \mathrm{P}_{\mathrm{cL}}=\mathrm{M}_{\mathrm{F}}\left(1+\Delta \mathrm{P}_{\mathrm{c}} / \mathrm{P}_{\mathrm{cL}}\right)=\mathrm{M}_{\mathrm{L}}^{0}-\mathrm{k}_{\mathrm{p}} \Delta \mathrm{P}_{\mathrm{c}} \cdot \mathrm{t}_{\mathrm{e}} \\
\Delta \mathrm{P}_{\mathrm{c}} / \mathrm{P}_{\mathrm{cL}}=\mathrm{k}_{\mathrm{p}} \Delta \mathrm{P}_{\mathrm{c}} \cdot\left(\mathrm{t}_{\mathrm{a}}-\mathrm{t}_{\mathrm{e}}\right) / \mathrm{M}_{\mathrm{F}} \Rightarrow \mathrm{t}_{\mathrm{e}}=\mathrm{t}_{\mathrm{a}}-\mathrm{M}_{\mathrm{F}} / \mathrm{P}_{\mathrm{cL}} \mathrm{k}_{\mathrm{p}}
\end{gathered}
$$

By eqns. (4), (6) it is observed that the $\Delta_{\mathrm{L}}{ }^{\mathrm{r}}$-triad becomes more efficient than $\Delta_{\mathrm{F}}$-triad in a shorter time $\mathrm{t}_{\mathrm{e}}$ when: $\Delta \mathrm{M} / \Delta \mathrm{P}_{\mathrm{c}} \rightarrow \mathrm{M}_{\mathrm{F}} / \mathrm{P}_{\mathrm{cL}}$, (if $\mathrm{M}_{\mathrm{L}}{ }^{0} \rightarrow \mathrm{M}_{\mathrm{F}}$ or $\Delta \mathrm{P}_{\mathrm{c}}=\mathrm{P}_{\mathrm{cF}}-\mathrm{P}_{\mathrm{cL}}$ is higher).

Similarly it may me studied the efficiency of the triad associated to the electric energy generating by a solar photovoltaic panel compared to those associated to a chemothermal moto-generator of electric energy.

C. Tetradic or pentadic CME triads

The cases with two causes C1, C2, (ex. wind energy + solar energy converted into kinetic energy of irrigation water (effect E) by means of an electric pump, (mean M)), or/and by two means M1, M2, (ex. - airplane engine + autopilot, for moving a plane on a predetermined route) or/and with two effects E1, E2, (ex. the effect E1 of precious metals recovery from electronic wastes + the effect E2 of environment's pollution), philosophically correspond to some tetradic or pentadic (or hexadic) triads, whose evolution can be studied similar to the case of a simple CME triad, with the difference that the graphical representation of the triad evolution will be made with an axial system that instead of a single axis $\mathrm{C}, \mathrm{M}$ or/and E will use two adjacent axes, (figure 2 - bi-causal CME triad). In the case of a triad with two effects the triad's efficiency $\epsilon_{\Delta}$ may be analyzed individually (separate for each effect) or globally - by the sumation of effects, as in the case of a triad with two causes or two means, taking the harmful effect as negative, resulting a global triad, $\Delta^{\mathrm{G}}$.

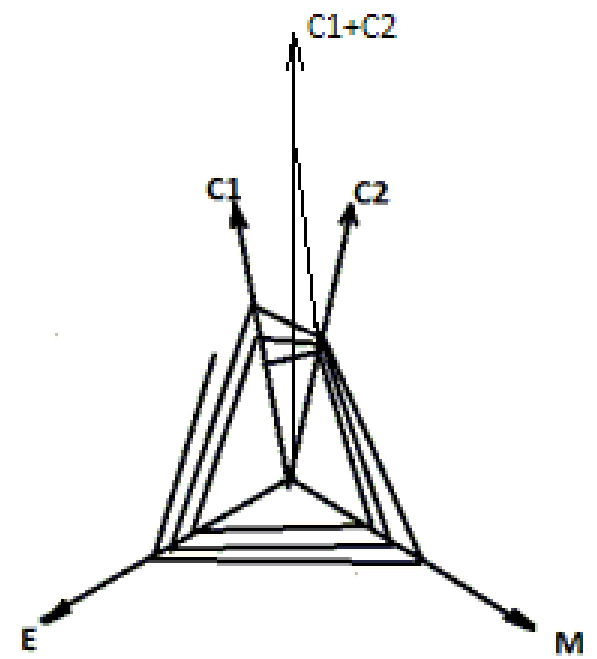

Figure 2. Increasing CME triad with two causes; (tetradic triad).

\section{The Approximation of the Use Value of M-means (particularly - Invention or Innovation)}

By comparing with different market products, it follows that the production value of a product considered as a mean $\mathrm{M}$ for converting a $\mathrm{C}$ cause into a socially useful $\mathrm{E}$ effect is proportional to the degree of complexity and its internal organization, which in systemic terms is can be expressed by the maximum entropy of the product (obtained at its total destruction) taken with the minus sign, (i.e. by the negentropy comprised by the product $\left(-S_{M}\right)$ ) and with the reliability of the product, $p(\tau)$, which represents the "confidence" that we can have in the product functioning for a longer period of time.

As it is known, the reliability theory (the "safety" theory [4]) describes in technique the probability " $p_{f}$ " as after a time $\tau$, a functional system with $\mathrm{N}$ components of which $\mathrm{n}_{1}$ components have the "lifetime" (service life) $T_{1}, n_{2}$ components have $\mathrm{T}_{2}$ lifetime, $\mathrm{n}_{\mathrm{i}}$ components have the lifetime $T_{i}$ etc., still work. This probability represents the reliability of the system (the possibility of "trust" in those system) and it is expressed by the "danger of failure" $\lambda_{i}$ of the component elements, being determined by the relations:

$$
\begin{aligned}
& p(\tau)=e^{-\Sigma\left(\lambda_{i} \cdot n_{i} \cdot \tau\right)} \\
& \lambda_{i}=\frac{1}{T_{i}}=\frac{\Delta n_{d i}}{n_{d i} \cdot \tau}=\frac{\mathrm{v}_{\mathrm{di}}}{\mathrm{n}_{\mathrm{di}}}
\end{aligned}
$$

with: $n_{i}$ - the number of elements in the sub-system " $i$ "; $T_{i}$ the average "functional life" of the sub-system "i" of the system; $\Delta \mathrm{n}_{\mathrm{di}}$-the number of faults that occur within the time interval $\tau ; \mathrm{n}_{\mathrm{di}}$ - the number of defects after which the subsystem "i" becomes inoperative (destroyed [5]); $\mathrm{v}_{\mathrm{di}}-$ the 
speed of destruction of the sub-system "i".

It can be shown mathematically [5] that in a general way, the reliability of a system which functions with $\mathrm{N}=\sum \mathrm{n}_{\mathrm{i}}$ component parts can be expressed also by a function representing the "operating potential" of the system (subsystem), having the expression:

$$
Q_{S}(\tau)=e^{\left(1-\Lambda_{S} \cdot \tau\right)}=Q_{S}^{M} \cdot p(\tau) ; \quad Q_{S}^{\mathrm{M}}=e ; \quad Q_{S}^{\mathrm{m}}=1
$$

in which the expression:

$$
\Lambda_{s}=\sum_{i=1}^{k} \lambda_{i} \cdot f_{i}=\frac{1}{T_{s}} ; \quad f_{\mathrm{i}}=n_{i} \cdot c
$$

represents the "danger of blocking" (functional destruction) of the system having the functional "life" duration " $\mathrm{T}_{\mathrm{s}}$ ", the factor "c" characterizing the influence of the connections between the components of the system, with: $\mathrm{c}=\mathrm{c}_{1} \mathrm{c}_{2} \sim(\mathrm{nr} \text {. of links) })^{-1}$, for informatical systems.

The operating potential of the system, previously defined, has the property that it is in the Boltzmann relation with the functional negentropy of the system, that is given according to the Boltzmann's relation, by the expression:

$$
\mathrm{O}_{\tau}=-\mathrm{S}_{\mathrm{M}} \ln \mathrm{Q}_{\mathrm{S}}=-\mathrm{S}_{\mathrm{M}}\left(1-\Lambda_{\mathrm{s}} \tau\right)=\mathrm{O}_{\mathrm{M}}+\mathrm{S}_{\mathrm{L}}
$$

in which the maximum negentropy has the value $\mathrm{O}_{M}=-S_{M}$ and the functional entropy (at the moment $\tau$ ) is:

$$
S_{\tau}=+S_{M} \cdot \Lambda_{s} \cdot \tau=\mathrm{S}_{\mathrm{M}} \cdot \tau \cdot \sum_{i=1}^{k} \lambda_{i} \cdot f_{i}
$$

$\mathrm{S}_{\mathrm{M}}$ representing the maximum entropy that the total disorganized system can have.

The use value of a mean $\mathrm{M}$ at a given $\tau_{0}$ moment can be empirically but generally approximated by a relation:

$$
\mathrm{M}_{\mathrm{p}}=\mathrm{k}_{\mathrm{M}}\left|\mathrm{O}_{\mathrm{M}}\right| \mathrm{Q}_{\mathrm{S}}\left(\tau_{0}\right)=\mathrm{k}_{\mathrm{M}} \mathrm{S}_{\mathrm{M}} \cdot \mathrm{Q}_{\mathrm{S}}\left(\tau_{0}\right)
$$

wherein: $\mathrm{O}_{M}$ - the embedded negentropy, $\mathrm{Q}_{\mathrm{S}}\left(\tau_{0}\right)$ - the operating potential of the M- mean(s) at the $\tau_{0}$-moment and $\mathrm{k}_{\mathrm{M}}$ is a quasi-constant of proportionality whose value is inversely proportional to the value of the utilities necessary for the maintaining of the reliability of the M- type product, for example, the oil, antifreeze liquid, etc. - in the case of a car engine- considered as $\mathrm{M}$-mean of converting the chemical energy of a fuel (gasoline, diesel) or the electrical energy of some batteries (cause C) into mechanical energy of moving the car (the effect E).

The use value of a physical mean $\mathrm{M}_{t}$ at a given moment $\tau$ may be approximated by eqns (9) and (13):

$$
M_{t}=k_{M} S_{M} Q_{S}(\tau)=K_{M} \cdot S_{M} \cdot p(\tau) ; \quad \mathrm{K}_{\mathrm{M}}=\mathrm{e} \cdot \mathrm{k}_{\mathrm{M}}
$$

In the case of a relative triad, the values of $\mathrm{k}_{\mathrm{M}}, \mathrm{K}_{\mathrm{M}}$ can decrease in time as in the example B3.

Generally, for a general physical system, the previous relations (13), (14) become more complex by the fact that similar to some technical systems, many non-technical systems: biophysical, ecological, etc., are also open functional systems. The man himself, in relation to the Nature and the Society, represents a subsystem with a certain medium and momentary potential for harmonizing the macrosystem (Nature + Society).

But- compared to a technical system, a psychological and a phycho-social system or even a technical but informatic system, may decrease its internal entropy in time, (increasing its internal organization) and the relations (7) $-(8)$, specific mainly to a technical system, are not applied, even if the relations (9)- (14) may be applied but with a more complex expression of the reliability $\mathrm{p}(\tau)$, in which the proportionality factor " $c$ " have the form: $c=c_{1} \cdot c_{2}$ because it depends not only on the connections between the components of the system, by $\mathrm{c}_{1}$, but also on the links between peripherical sensors + informational database and the informations processing unit, (microprocessor- for an informatical system, or brain- for a psycho-biological system), by $c_{2}$, being known that -for a brain, the number of neuronal links, $\mathrm{n}_{\mathrm{l}}$, increases by learning, $\left(c_{2} \sim(n r \text {. of links between neurons })^{-1}=1 / n_{1}\right)$.

The previous conclusions are in concordance with the fact that generally the systems have component parts which are in their turn systems (subsystems), thus forming a "holon" [6], a collective unit ("holos" = "whole"), part of a larger one.

The holons of a system interfere with each other and through this they increase or decrease each other's their organizing (or their entropy). If the holons increase each other's organizing, we can talk about their harmonization, and if they decrease their functional organization, it results their disharmony.

The philosophical considerations about the approximating of the efficiency of a CME- triad and the examples presented for it, although not strictly accurate, can be used in the field of philosophy of technology, for example - in estimating the risk of the environmental destruction through the evolution of a technical CME- triad, (ex. -the risk of chemical pollution by oil or gold extraction technology, etc.).

\section{Conclusions}

The proposed method of approximating the efficiency of a Cause-Mean-Effect (CME) triad of technical or non-technical nature, considered with cyclical and variable evolution, is based by a graphical representation with three axes in which the position on its axis of representation of the cause $\mathrm{C}$ or of the effect $\mathrm{E}$ indicates its intensity and the position on its axis of representation of the mean $M$ represents its value expressed by the amount of the intrinsic negentropy: $\mathrm{O}_{M}=$ $\mathrm{S}_{\mathrm{M}}$ and its reliability $\mathrm{p}(\tau)$, the efficiency of the CME triad being approximated in a simplified form as given by the product of the ratios $(E / M)$ and $(E / C): \in \approx E^{2} / M \cdot C$.

A relevant particular case of analysis of a technical CME triad is those of the relative efficiency $\epsilon_{\mathrm{L}}$ of an electric bulb with LEDs comparative with the efficiency $\epsilon_{\mathrm{F}}$ of an electric bulb with filament, in which the use value $\mathrm{M}_{\mathrm{L}}$ of the 
compared electric bulb must be considered variable in an initial period of time, for a comparative study, when $\epsilon_{\mathrm{L}}$ is not from the beginning (on a short time period) higher than $\epsilon_{\mathrm{F}}$.

The proposed method, in the variant of tetradic triad with two different positive effects E1, E2 and a single cause and a single mean, is linked also -in the phylosophy of technology, with the principle of the economy by 'agglomeration of results', (economy by 'doing two different things by one stroke'- Kotarbiński, 1965, p. 109, [7],). A technical example in this sense is the result (effect E1) of electric energy generating with increase efficiency by the wind energy conversion (the cause, $\mathrm{C}$ ) with a wind turbine with magnetic bearing (the mean, M), for which the magnetic bearing gives also a secondary positive result (effect E2): the turbine's noise reduction. The associated $\mathrm{CME}$ triad is a tetradic oscillatory triad, with variable E1-effect proportional with the wind's intensity variation, whose efficiency may be studied as relative efficiency, as in the example B4, either individually, only for the effect E1 or E2 or globally, for the effect $E^{\mathrm{G}}=\mathrm{E} 1+\mathrm{E} 2$-by expressing the effect's value by the same measure unit.

The use value of the mean $M$ can be empirically but generally approximated by a relation: $\mathrm{M}=\mathrm{K}_{\mathrm{M}} \cdot \mathrm{S}_{\mathrm{M}} \cdot \mathrm{p}(\tau)$ wherein: $S_{M}$ is the maximal possible intrinsic entropy and $K_{M}$ is a quasi-constant of proportionality whose value is inversely proportional to the value of the utilities necessary for the maintaining of the reliability of the M-mean.

A special case is represented by the systems with capability to au-decrease their internal entropy, such as a psychological, a phycho-social system or even a technical but informatic system, which- compared to a technical system, may increase their internal organization, for which the $p(\tau)$ reliability' expression is more complex than those of a physical/technical system, it depending also on a factor "c" characterizing the influence of the connections between the components of the system, with: $\mathrm{c}=\mathrm{c}_{1} \mathrm{c}_{2} \sim(\mathrm{nr} \text {. of links })^{-1}$ for informatical / neuronal systems.

An example of the method's application to a complex system is those of the managerial malpractice increasing in a state institution, (political, economical or administrative), by a low reliability $\mathrm{p}(\tau)$ of the institution's manager or by a low technoscientization of the institution.

From the presented examples it results that the proposed method have links also with the domain of the praxiology [8], [9], with the phylosophy of science and with the domain of the technoscience [10], particularly- also with the politic's technoscientization, (Callon [11], Cetina [12], Hacking [13]).

The presented examples of the method's application for the studiyng of technical or non-technical or mixed systems, reveals the possibility of the method's using also in the domain of philosophy of technology, in particular - in assessing the risk of the society's regression by the degrading of the environment or by the excessive exploitation of natural resources.

\section{References}

[1] Ernst Kapp, "Grundlinien einer Philosophie der Technik. Zur Entstehungsgeschichte der Cultur aus neuen Gesichtspunkten" (Braunschweig/Brunswick (1877), Reprint Düsseldorf (1978), Engl. Translation Chicago (1978).

[2] Green, Lelia, "Technoculture", Crows Nest, Australia: Allen \& Unwin., (2001), p. 2.

[3] S. Băiculescu, "Triades", Ses. Com. Of GCI- Group of Romanian Acad., Bucharest, 14 nov. (2019).

[4] Gnedenko B. V., Beleaev I. K., "Mathematical methods in the fiability theory”, Ed. Tehnică, Bucharest, (1968).

[5] Arghirescu M., "The Cold Genesis of Matter and Fields", Ed. SciencePG, (2015). Arghirescu M., "The Matter's Genesis and Field Effects", Ed. MatrixRom, Bucharest, (2006).

[6] Solomon Marcus, "The Paradoxe", Ed. Albatros, Bucharest, (1984).

[7] Kotarbiński, T., 'Praxiology: An Introduction to the Sciences of Efficient Action', Oxford, Pergamon Press, (1965).

[8] R. W. Revans, 'Action, creativity and learning: Some reflections upon the nature of achievement', Prakseologia No. 39/40, (1971), pp. 29-50.

[9] P. Makowski, M. Bonecki, \& K. Nowak-Posadzy (Eds.), 'Praxiology and the Reasons for Action', Chpt. 2: 'Praxiology Meets Planning Theory of Intention. Kotarbiński and Bratman on Plans, New Brunswick, Transaction Publishers (2015), pp. 43-71.

[10] G. Cutting, ,Gaston Bachelard's philosophy of science' International Studies in the Philosophy of Science, Vol. 2, Iss. 1, (1987).

[11] Callon et al., 'Acting in an Uncertain world', The MIT Press, Cambridge, London, (2009): 46-70.

[12] Knorr Cetina K., "Laboratory Studies: The Cultural Approach to the Study of Science," In: Jasanoff S, ed. Handbook of science and technology studies, Los Angeles, (1995).

[13] Ian Hacking, "Representing and Intervieving, Topics in the Phylosophy of Natural Science" Cambridge Univ. Press, (1983). 